\title{
A protocol for the measurement of myocardial blood volume and water exchange
}

\author{
Octavia Biris ${ }^{*}$, Neil Chatterjee, James Carr \\ From 2011 SCMR/Euro CMR Joint Scientific Sessions \\ Nice, France. 3-6 February 2011
}

\section{Objective}

Absolute myocardial perfusion MR imaging $(\mathrm{ml} / \mathrm{min} /$ $100 \mathrm{~g}$ tissue) has the potential to timely diagnose and reduce patient mortality from coronary artery disease.

\section{Background}

Organ perfusion can be quantified by direct calibration of relative perfusion images using absolute blood volume $(\mathrm{ml} / 100 \mathrm{~g})$ [1]. It is well known that for an intravascular gadolinium-based T1 shortening contrast agent, the parenchymal $\mathrm{T} 1$ change reflects tissue blood volume [2]. However, to accurately quantify blood flow from blood volume, we must describe the compartmentalization effects of intra- to extra-vascular water exchange $[2,3]$.

\section{Materials and methods \\ Protocol}

In an instrumented dog we measured T1 using a cardiac gated Modified Look Locker Inversion Recovery (MOLLI)(4) pulse sequence (slice thickness $8 \mathrm{~mm}$, FOV $171 \times 343 \mathrm{~mm} 2$, matrix 96 x192, TR $173 \mathrm{~ms}$, effective TI $100 \mathrm{~ms}$ ). Images were acquired on a $1.5 \mathrm{~T}$ Espree scanner (Siemens Medical Systems, Erlangen, Germany), during a short breath-hold, 5 minutes after injections of $0.003 \mathrm{mmol} / \mathrm{kg}$ of MS-325 (Ablavar, Lantheus Medical Imaging, Billerica, MA).

\section{Image processing}

We estimated the myocardium and left ventricle blood pool T1 through fitting of MOLLI signal to the regrowth curves of the Look-Locker equation by an automatic image processing program developed in

Northwestern University, Chicago, IL, USA

Table 1 Blood pool and myocardium T1

\begin{tabular}{lllllll}
\hline & Baseline & $\begin{array}{l}\mathbf{0 . 0 0 3} \\
\mathbf{m m o l} /\end{array}$ & $\begin{array}{l}\mathbf{0 . 0 0 9} \\
\mathbf{m m o l} /\end{array}$ & $\begin{array}{l}\mathbf{0 . 0 1 5} \\
\mathbf{m m o l} /\end{array}$ & $\begin{array}{l}\mathbf{0 . 0 2 1} \\
\mathbf{m m o l} /\end{array}$ & $\begin{array}{l}\mathbf{0 . 0 2 7} \\
\mathbf{~ m m o l} /\end{array}$ \\
& & $\mathbf{k g}$ & $\mathbf{k g}$ & $\mathbf{k g}$ & $\mathbf{k g}$ & $\mathbf{~ k g}$ \\
\hline T1 in left & $1259 \pm 63$ & 1018 & 761 & 645 & 580 & 548 \\
ventricle blood & & \pm 33 & \pm 15 & \pm 19 & \pm 16 & \pm 33 \\
pool (ms) & & & & & & \\
T1 in & $871 \pm 88$ & 818 & 727 & 676 & 634 & 624 \\
myocardium & & \pm 76 & \pm 52 & \pm 49 & \pm 69 & \pm 42 \\
(ms) & & & & & &
\end{tabular}

MATLAB R2009a (Mathworks, Natick, MA, USA). Myocardial blood volume (MBV) was calculated from the baseline to post-contrast change in $\mathrm{T} 1$ in the blood pool and myocardium.

\section{Results}

Low dose injections (1/10th of single dose for humans) of MS-325 effected significant changes in myocardial T1's (Table 1). The measured MBV was $40 \%$ of total myocardial volume, or $28 \mathrm{ml} / 100 \mathrm{~g}$, a value that overestimates those quoted in the literature [5]. Water exchange in the myocardium was shown to approach the slow or no-exchange limit (Figure 1).

\section{Conclusions}

We have established an imaging protocol to measure $M B V$ and water exchange. Over-estimation of MBV may be caused by extravasation of MS-325, and to a lesser extent by T2 bias on the T1 measurements with the steady-state free precession MOLLI sequence. Future steps include measuring MBV with a strictly intravascular USPIO contrast agent, application of a more sophisticated fit that includes T2 effects, and determination of the water exchange constant by Monte-Carlo simulations. 


\section{MBV Calculations Show Slow Water Proton \\ Exchange}
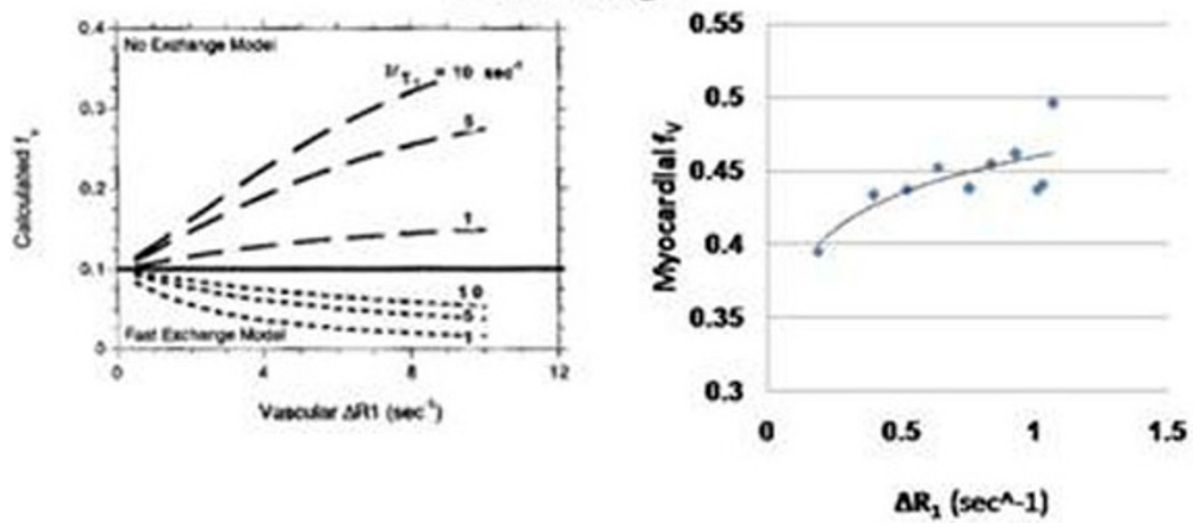

Figure 1 Vascular fractions fv predictions based on "No exchange" and fast exchange limits for a range of exchange values (left). Preliminary results from our experiments suggest the "No exchange" limit is appropriate for the quantification of myocardial blood volume (right).

Published: 2 February 2011

\section{References}

1. Carroll TJ, Horowitz S, et al: Magn Reson Imaging 2008, 26(10):1352-9.

2. Donahue KM, Weisskoff RM, et al: Magn Reson Med 1996, 36(6):858-67.

3. Hazlewood CF, Chang DC, et al: Biophys J 1974, 14(8):583-606.

4. Messroghli DR, Radjenovic A, et al: Magn Reson Med 2004, 52(1):141-6.

5. Bjornerud A, Bjerner T, et al: Magn Reson Med 2003, 49(5):828-37.

doi:10.1186/1532-429X-13-S1-P140

Cite this article as: Biris et al:: A protocol for the measurement of

myocardial blood volume and water exchange. Journal of Cardiovascular

Magnetic Resonance 2011 13(Suppl 1):P140.

Submit your next manuscript to BioMed Central and take full advantage of:

- Convenient online submission

- Thorough peer review

- No space constraints or color figure charges

- Immediate publication on acceptance

- Inclusion in PubMed, CAS, Scopus and Google Scholar

- Research which is freely available for redistribution 